\title{
Hybrid DE-SQP Method for Solving Combined Heat and Power Dynamic Economic Dispatch Problem
}

\author{
A. M. Elaiw, ${ }^{1,2}$ X. Xia, ${ }^{3}$ and A. M. Shehata ${ }^{2}$ \\ ${ }^{1}$ Department of Mathematics, Faculty of Science, King Abdulaziz University, P.O. Box 80203, Jeddah 21589, Saudi Arabia \\ ${ }^{2}$ Department of Mathematics, Faculty of Science, Al-Azhar University, Assiut 71511, Egypt \\ ${ }^{3}$ Centre of New Energy Systems, Department of Electrical, Electronic and Computer Engineering, University of Pretoria, \\ Pretoria 0002, South Africa
}

Correspondence should be addressed to A. M. Elaiw; a_m_elaiw@yahoo.com

Received 19 June 2013; Accepted 25 August 2013

Academic Editor: Carla Roque

Copyright $\odot 2013$ A. M. Elaiw et al. This is an open access article distributed under the Creative Commons Attribution License, which permits unrestricted use, distribution, and reproduction in any medium, provided the original work is properly cited.

Combined heat and power dynamic economic dispatch (CHPDED) plays a key role in economic operation of power systems. CHPDED determines the optimal heat and power schedule of committed generating units by minimizing the fuel cost under ramp rate constraints and other constraints. Due to complex characteristics, heuristic and evolutionary based optimization approaches have became effective tools to solve the CHPDED problem. This paper proposes hybrid differential evolution (DE) and sequential quadratic programming (SQP) to solve the CHPDED problem with nonsmooth and nonconvex cost function due to valve point effects. DE is used as a global optimizer and SQP is used as a fine tuning to determine the optimal solution at the final. The proposed hybrid DE-SQP method has been tested and compared to demonstrate its effectiveness.

\section{Introduction}

In the past decades, increasing demand for power and heat resulted in the existence of combined heat and power (CHP) units, known as cogeneration or distributed generation. It produces electricity and useful heat simultaneously. While the efficiency of the normal power generation is between $50 \%$ and $60 \%$, the power and heat cogeneration increases the efficiency around 90\% [1]. Utilization of CHP units besides conventional thermal power generating units and heat-only units to satisfy heat and power load demands in an economical manner emphasizes the need to combined heat and power economic dispatch (CHPED). The objective of the CHPED problem is to determine both power generation and heat production from units by minimizing the fuel cost such that both heat and power demands are met while the combined heat and power units are operated in a bounded heat versus power plane. For most CHP units, the heat production capacities depend on the power generation. This mutual dependency of the CHP units introduce a complication to the problem [2]. In addition, considering valve point effects in the CHPED problem makes the problem nonsmooth with multiple local optimal point which makes finding the global optimal challenging.

Over the past few years, a number of approaches have been developed for solving the CHPED problem with complex objective functions or constraints such as Lagrangian Relaxation (LR) [3, 4], Semidefinite Programming (SDP) [5], augmented Lagrange combined with Hopfield neural network [6], Harmony Search (HS) algorithm [1, 7], Genetic Algorithm (GA) [8], Ant Colony Search Algorithm (ACSA) [9], Mesh Adaptive Direct Search (MADS) algorithm [10], Self Adaptive Real-Coded Genetic Algorithm (SARGA) [2], Particle Swarm Optimization (PSO) [11, 12], Artificial Immune System (AIS) [13], and Evolutionary Programming (EP) [14]. In [11, 13], the valve point effects and the transmission line losses are incorporated into the CHPED problem.

The main drawbacks of the CHPED is that it may fail to deal with the large variations of the heat and power load demands due to the ramp rate limits of the units; moreover, it does not have the look-ahead capability. To overcome these drawbacks, combined heat and power dynamic economic dispatch (CHPDED) problem is formulated with the objective to determine the optimal heat and power schedule of 
the committed units so as to meet the predicted heat and power load demands over a time horizon at minimum operating cost under ramp rate constraints and other constraints [15]. CHPDED has a look-ahead capability which is necessary to schedule the load beforehand so that the system can anticipate sudden changes in power and heat demands in the near future. The ramp rate constraint is a dynamic constraint which is important to maintain the life of the generators [16]. Since the ramp rate constraint couples the time intervals, the CHPDED problem is a difficult optimization problem. If the ramp rate constraint is not included in the optimization problem, the CHPDED problem is reduced to a set of uncoupled CHPED problems that can easily be solved. The traditional dynamic economic dispatch (DED) problem which considers only conventional thermal units that provide only electric power has been studied by several authors (see e.g., $[17,18]$ and the review paper [16]). However, the CHPDED problem has only been considered in $[15,19]$.

Differential Evolution (DE) algorithm, which was proposed by Storn and Price [20] is a population-based stochastic parallel search technique. DE uses a rather greedy and less stochastic approach to problem solving compared to other evolutionary algorithms. DE has the ability to handle optimization problems with nonsmooth/nonconvex objective functions [20]. Moreover, it has a simple structure and a good convergence property, and it requires a few robust control parameters [20]. DE has been applied to the CHPED problem with nonsmooth and nonconvex cost functions in [21].

The DE shares many similarities with evolutionary computation techniques such as Genetic Algorithms (GA) techniques. The system is initialized with a population of random solutions and searches for optima by updating generations. DE has evolution operators such as crossover and mutation. Although DE seems to be a good method to solve the CHPDED problem with nonsmooth and nonconvex cost functions, solutions obtained are just near global optimum with long computation time. Therefore, hybrid methods such as DE-SQP can be effective in solving the CHPDED problem with valve-point effects. Hybrid DE-SQP method has been used for solving the DED problem in $[22,23]$.

The aim of this paper is to propose a hybrid DE-SQP method for solving the CHPDED problem with nonsmooth and nonconvex objective function. DE is used as a base level search for global exploration and SQP is used as a local search to fine-tune the solution obtained from DE. The effectiveness of the proposed method is shown for test system.

\section{Problem Formulation}

In this section, we formulate the CHPDED problem. The system under consideration has three types of generating units, conventional thermal units (TU), CHP units, and heat-only units $(H)$. The power is generated by conventional thermal units and CHP units, while the heat is generated by CHP units and heat-only units. The objective of the CHPDED problem is to minimize the system's production cost so as to meet the predicted heat and power load demands over a time horizon under ramp rate and other constraints. The following objectives and constraints are taken into account in the formulation of the CHPDED problem.

2.1. Objective Functions. In this section, we introduce the cost function of three types of generating units, conventional thermal units, CHP units, and heat-only units.

Conventional Thermal Units. The cost function curve of a conventional thermal unit can be approximated by a quadratic function $[24,25]$. Power plants commonly have multiple valves which are used to control the power output of the unit. When steam admission valves in conventional thermal units are first open, a sudden increase in losses is registered which results in ripples in the cost function $[16,26]$. This phenomenon is called as valve-point effects. The generator with valve-point effects has very different input-output curve compared with smooth cost function. Taking the valve-point effects into consideration, the fuel cost is expressed as the sum of a quadratic and sinusoidal functions $[17,19,27]$. Therefore, the fuel cost function of the conventional thermal units is given by

$$
\begin{aligned}
& C_{i}^{\mathrm{TU}}\left(P_{i, t}^{\mathrm{TU}}\right) \\
& \quad=a_{i}+b_{i} P_{i, t}^{\mathrm{TU}}+c_{i}\left(P_{i, t}^{\mathrm{TU}}\right)^{2}+\left|e_{i} \sin \left(f_{i}\left(P_{i, \text { min }}^{\mathrm{TU}}-P_{i, t}^{\mathrm{TU}}\right)\right)\right|,
\end{aligned}
$$

where $a_{i}, b_{i}$, and $c_{i}$ are positive constants, $e_{i}$ and $f_{i}$ are the coefficients of conventional thermal unit $i$ reflecting valvepoint effects, $P_{i, t}^{\mathrm{TU}}$ is the power generation of conventional thermal unit $i$ during the $t$ th time interval $[t-1, t), P_{i \text {,min }}^{\mathrm{TU}}$ is the minimum capacity of conventional thermal unit $i$, and $C_{i}^{\mathrm{TU}}\left(P_{i, t}^{\mathrm{TU}}\right)$ is the fuel cost of conventional thermal unit $i$ to produce $P_{i, t}^{\mathrm{TU}}$.

CHP Units. A CHP unit has a convex cost function in both power and heat. The form of the fuel cost function of CHP units can be given by $[5,19]$

$$
\begin{aligned}
C_{j}^{\mathrm{CHP}} & \left(P_{j, t}^{\mathrm{CHP}}, H_{j, t}^{\mathrm{CHP}}\right) \\
= & \bar{a}_{j}+\bar{b}_{j} P_{j, t}^{\mathrm{CHP}}+\bar{c}_{j}\left(P_{j, t}^{\mathrm{CHP}}\right)^{2}+\bar{d}_{j} H_{j, t}^{\mathrm{CHP}} \\
& +\bar{e}_{j}\left(H_{j, t}^{\mathrm{CHP}}\right)^{2}+\bar{f}_{j} P_{j, t}^{\mathrm{CHP}} H_{j, t}^{\mathrm{CHP}}
\end{aligned}
$$

where $C_{j}^{\mathrm{CHP}}\left(P_{j, t}^{\mathrm{CHP}}, H_{j, t}^{\mathrm{CHP}}\right)$ is the generation fuel cost of $\mathrm{CHP}$ unit $i$ to produce power $P_{j, t}^{\mathrm{CHP}}$ and heat $H_{j, t}^{\mathrm{CHP}}$. Constants $\bar{a}_{j}, \bar{b}_{j}, \bar{c}_{j}, \bar{d}_{j}, \bar{e}_{j}$, and $\bar{f}_{j}$ are the fuel cost coefficients of CHP unit $j$.

Heat-Only Units. Cost: The cost function of heat-only units can take the following form $[5,19]$ :

$$
C_{k}^{H}\left(H_{k, t}^{H}\right)=\widetilde{a}_{k}+\widetilde{b}_{k} H_{k, t}^{H}+\widetilde{c}_{k}\left(H_{k, t}^{H}\right)^{2},
$$


where $\widetilde{a}_{k}, \widetilde{b}_{k}$, and $\widetilde{c}_{k}$, are the fuel cost coefficients of heat-only unit $k$ and they are constants.

Let $N$ be the number of dispatch intervals and let $N_{p}+$ $N_{c}+N_{h}$ be the number of committed units, where $N_{p}$ is the number of conventional thermal units, $N_{c}$ is the number of the CHP units, and $N_{h}$ is the number of the heat-only units. Then the total fuel cost over the dispatch period $[0, N]$ is given by

$$
\begin{aligned}
& C(\mathbf{P H}) \\
& =\sum_{t=1}^{N}\left(\sum_{i=1}^{N_{p}} C_{i}^{\mathrm{TU}}\left(P_{i, t}^{\mathrm{TU}}\right)+\sum_{j=1}^{N_{c}} C_{j}^{\mathrm{CHP}}\left(P_{j, t}^{\mathrm{CHP}}, H_{j, t}^{\mathrm{CHP}}\right)\right. \\
& \left.+\sum_{k=1}^{N_{h}} C_{k}^{H}\left(H_{k, t}^{H}\right)\right),
\end{aligned}
$$

where $\mathbf{P H}=\left(\mathbf{P H}_{1}, \mathbf{P H}_{2}, \ldots, \mathbf{P H}_{t}, \ldots, \mathbf{P H}_{N}\right)^{\prime}, \mathbf{P H}_{t}=\left(\mathbf{P}_{t}^{\mathrm{TU}}\right.$, $\left.\mathbf{P}_{t}^{\mathrm{CHP}}, \mathbf{H}_{t}^{\mathrm{CHP}}, \mathbf{H}_{t}^{H}\right)^{\prime}, \mathbf{P}_{t}^{\mathrm{TU}}=\left(P_{1, t}^{\mathrm{TU}}, P_{2, t}^{\mathrm{TU}}, \ldots, P_{N_{p}, t}^{\mathrm{TU}}\right)^{\prime}, \mathbf{P}_{t}^{\mathrm{CHP}}=$ $\left(P_{1, t}^{\mathrm{CHP}}, P_{2, t}^{\mathrm{CHP}}, \ldots, P_{N_{c}, t}^{\mathrm{CHP}}\right)^{\prime}, \mathbf{H}_{t}^{\mathrm{CHP}}=\left(H_{1, t}^{\mathrm{CHP}}, H_{2, t}^{\mathrm{CHP}}, \ldots, H_{N_{c}, t}^{\mathrm{CHP}}\right)^{\prime}$, and $\mathbf{H}_{t}^{H}=\left(H_{1, t}^{H}, H_{2, t}^{H}, \ldots, H_{N_{h}, t}^{H}\right)^{\prime}$.

The CHPDED problem can be mathematically formulated as a nonlinear constrained optimization problem as

$$
\min _{\mathbf{P H}} C(\mathbf{P H})
$$

subject to the constraints.

Power production and demand balance:

$$
\sum_{i=1}^{N_{p}} P_{i, t}^{\mathrm{TU}}+\sum_{j=1}^{N_{c}} P_{j, t}^{\mathrm{CHP}}=P_{D, t}+\text { Loss }_{t}, \quad t=1, \ldots, N
$$

where $P_{D, t}$ and Loss $_{t}$ are the system power demand and transmission line losses at time $t$ (i.e., the $t$ th time interval), respectively. The $\mathrm{B}$-coefficient method is one of the most commonly used methods by power utility industry to calculate the network losses. In this method, the network losses are expressed as a quadratic function of the unit's power outputs that can be approximated in the following:

$$
\text { Loss }_{t}=\sum_{i=1}^{N_{p}+N_{c}} \sum_{j=1}^{N_{p}+N_{c}} \mathbf{P L}_{i, t} B_{i j} \mathbf{P L}_{j, t} \quad t=1, \ldots, N,
$$

where

$$
\mathbf{P L}_{i, t}= \begin{cases}P_{i, t}^{\mathrm{TU}}, & i=1, \ldots, N_{p}, \\ P_{i-N_{p}, t}^{\mathrm{CHP}}, & i=N_{p}+1, \ldots, N_{p}+N_{c},\end{cases}
$$

and $B_{i j}$ is the $i j$ th element of the loss coefficient square matrix of size $N_{p}+N_{c}$.

Heat production and demand balance:

$$
\sum_{j=1}^{N_{c}} H_{j, t}^{\mathrm{CHP}}+\sum_{k=1}^{N_{h}} H_{k, t}^{H}=H_{D, t}, \quad t=1, \ldots, N
$$

where $H_{D, t}$ is the system heat demand at time $t$.

Capacity limits of conventional thermal units:

$$
P_{i, \min }^{\mathrm{TU}} \leq P_{i, t}^{\mathrm{TU}} \leq P_{i, \max }^{\mathrm{TU}}, \quad i=1, \ldots, N_{p}, t=1, \ldots, N,
$$

where $P_{i, \min }^{\mathrm{TU}}$ and $P_{i, \max }^{\mathrm{TU}}$ are the minimum and maximum power capacities of conventional thermal unit $i$, respectively.

Capacity limits of CHP units:

$$
\begin{array}{r}
P_{j, \text { min }}^{\mathrm{CHP}}\left(H_{j, t}^{\mathrm{CHP}}\right) \leq P_{j, t}^{\mathrm{CHP}} \leq P_{j, \max }^{\mathrm{CHP}}\left(H_{j, t}^{\mathrm{CHP}}\right), \\
j=1, \ldots, N_{c}, \quad t=1, \ldots, N, \\
H_{j, \min }^{\mathrm{CHP}}\left(P_{j, t}^{\mathrm{CHP}}\right) \leq H_{j, t}^{\mathrm{CHP}} \leq H_{j, \max }^{\mathrm{CHP}}\left(P_{j, t}^{\mathrm{CHP}}\right), \\
j=1, \ldots, N_{c}, \quad t=1, \ldots, N,
\end{array}
$$

where $P_{j, \min }^{\mathrm{CHP}}\left(H_{j, t}^{\mathrm{CHP}}\right)$ and $P_{j, \max }^{\mathrm{CHP}}\left(H_{j, t}^{\mathrm{CHP}}\right)$ are the minimum and maximum power limits of CHP unit $j$, respectively, and they are functions of generated heat $\left(H_{j, t}^{\mathrm{CHP}}\right) . H_{j \text {,min }}^{\mathrm{CHP}}\left(P_{j, t}^{\mathrm{CHP}}\right)$ and $H_{j, \text { max }}^{\mathrm{CHP}}\left(P_{j, t}^{\mathrm{CHP}}\right)$ are the heat generation limits of CHP unit $j$ which are functions of generated power $\left(P_{j, t}^{\mathrm{CHP}}\right)$.

Capacity limits of heat-only units:

$$
H_{k, \text { min }}^{H} \leq H_{k, t}^{H} \leq H_{k, \text { max }}^{H}, \quad k=1, \ldots, N_{h}, t=1, \ldots, N
$$

where $H_{k \text {,min }}^{H}$ and $H_{k \text {,max }}^{H}$ are the minimum and maximum heat capacities of heat-only unit $k$, respectively.

Upper/down ramp rate limits of conventional thermal units:

$$
\begin{gathered}
-D R_{i}^{\mathrm{TU}} \leq P_{i, t+1}^{\mathrm{TU}}-P_{i, t}^{\mathrm{TU}} \leq U R_{i}^{\mathrm{TU}}, \\
i=1, \ldots, N_{p}, \quad t=1, \ldots, N-1,
\end{gathered}
$$

where $U R_{i}^{\mathrm{TU}}$ and $D R_{i}^{\mathrm{TU}}$ are the maximum ramp up/down rates for conventional thermal unit $i[16]$.

Upper/down ramp rate limits of CHP units:

$$
\begin{gathered}
-D R_{j}^{\mathrm{CHP}} \leq P_{j, t+1}^{\mathrm{CHP}}-P_{j, t}^{\mathrm{CHP}} \leq U R_{j}^{\mathrm{CHP}}, \\
j=1, \ldots, N_{c}, \quad t=1, \ldots, N-1,
\end{gathered}
$$

where $U R_{j}^{\mathrm{CHP}}$ and $D R_{j}^{\mathrm{CHP}}$ are the maximum ramp up/down rates for CHP unit $j$ [19].

\section{Differential Evolution Method}

DE is a simple yet powerful heuristic method for solving nonlinear, nonconvex, and nonsmooth optimization problems. $\mathrm{DE}$ algorithm is a population-based algorithm using three operators: mutation, crossover, and selection to evolve from randomly generated initial population to final individual solution [20]. In the initialization, a population of NP target vectors (parents) $X_{i}=\left\{x_{1 i}, x_{2 i}, \ldots, x_{D i}\right\}, i=1,2, \ldots, N P$ is randomly generated within user-defined bounds, where $D$ is the dimension of the optimization problem. Let $X_{i}^{G}=$ $\left\{x_{1 i}^{G}, x_{2 i}^{G}, \ldots, x_{D i}^{G}\right\}$ be the individual $i$ at the current generation 
TABLE 1: Data of the CHP units and heat-only unit of the eleven-unit system.

\begin{tabular}{lccccccc}
\hline CHP units & $\bar{a}_{j}$ & $\bar{b}_{j}$ & $\bar{c}_{j}$ & $\bar{d}_{j}$ & $\bar{e}_{j}$ & $\bar{f}_{j}$ & $D R_{j}^{\mathrm{CHP}}=U R_{j}^{\mathrm{CHP}}$ \\
\hline$j=1$ & 2650 & 14.5 & 0.0345 & 4.2 & 0.030 & 0.031 & 70 \\
$j=2$ & 1250 & 36 & 0.0435 & 0.6 & 0.027 & 0.011 & 50 \\
\hline \multicolumn{2}{c}{ Heat-only units } & $H_{k, \max }^{H}$ & $H_{k, \text { min }}^{H}$ & $\widetilde{a}_{k}$ & $\widetilde{b}_{k}$ & $\widetilde{c}_{k}$ & \\
\multicolumn{2}{c}{$k=1$} & 2695.2 & 0 & 950 & 2.0109 & 0.038 \\
\hline
\end{tabular}

TABLE 2: Heat load demand of the eleven-unit system.

\begin{tabular}{lc}
\hline Time (h) & Demand (MWth) \\
\hline 1 & 390 \\
2 & 400 \\
3 & 410 \\
4 & 420 \\
5 & 440 \\
6 & 450 \\
7 & 450 \\
8 & 455 \\
9 & 460 \\
10 & 460 \\
1 & 470 \\
12 & 480 \\
13 & 470 \\
14 & 460 \\
15 & 450 \\
16 & 450 \\
17 & 420 \\
18 & 435 \\
19 & 445 \\
20 & 450 \\
21 & 445 \\
22 & 435 \\
23 & 400 \\
24 & 400 \\
\hline
\end{tabular}

G. A mutant vector $V_{i}^{G+1}=\left(v_{1 i}^{G+1}, v_{2 i}^{G+1}, \ldots, v_{D i}^{G+1}\right)$ is generated according to

$$
\begin{gathered}
V_{i}^{G+1}=X_{r_{1}}^{G}+\mathscr{F} \times\left(X_{r_{2}}^{G}-X_{r_{3}}^{G}\right), \\
r_{1} \neq r_{2} \neq r_{3} \neq i, \quad i=1,2, \ldots, N P
\end{gathered}
$$

with randomly chosen integer indexes $r_{1}, r_{2}, r_{3} \in\{1,2, \ldots$, $N P\}$. Here $\mathscr{F}$ is the mutation factor.

According to the target vector $X_{i}^{G}$ and the mutant vector $V_{i}^{G+1}$, a new trial vector (offspring) $U_{i}^{G+1}=\left\{u_{1 i}^{G+1}\right.$, $\left.u_{2 i}^{G+1}, \ldots, u_{D i}^{G+1}\right\}$ is created with

$$
u_{j i}^{G+1}= \begin{cases}v_{j i}^{G+1} & \text { if }(\operatorname{rand}(j) \leq C R) \text { or } j=r n b(i) \\ x_{j i}^{G} & \text { otherwise }\end{cases}
$$

where $j=1,2, \ldots, D, i=1,2, \ldots, N P$, and $\operatorname{rand}(j)$ is the $j$ th evaluation of a uniform random number between $[0,1]$.
$C R \in[0,1]$ is the crossover constant which has to be determined by the user. $r n b(i)$ is a randomly chosen index from $1,2, \ldots, D$ which ensures that $U_{i}^{G+1}$ gets at least one parameter from $V_{i}^{G+1}$ [20].

The selection process determines which of the vectors will be chosen for the next generation by implementing one-to-one competition between the offsprings and their corresponding parents. If $f$ denotes the function to be minimized, then

$$
X_{i}^{G+1}= \begin{cases}U_{i}^{G+1} & \text { if } f\left(U_{i}^{G+1}\right) \leq f\left(X_{i}^{G}\right) \\ X_{i}^{G} & \text { otherwise, }\end{cases}
$$

where $i=1,2, \ldots, N P$. The value of $f$ of each trial vector $U_{i}^{G+1}$ is compared with that of its parent target vector $X_{i}^{G}$. The above iteration process of reproduction and selection will continue until a user-specified stopping criteria is met.

In this paper, we define the evaluation function for evaluating the fitness of each individual in the population in DE algorithm as follows:

$$
\begin{aligned}
f= & C+\lambda_{1} \sum_{t=1}^{N}\left(\sum_{i=1}^{N_{p}} P_{i, t}^{\mathrm{TU}}+\sum_{j=1}^{N_{c}} P_{j, t}^{\mathrm{CHP}}-\left(P_{D, t}+\text { Loss }_{t}\right)\right)^{2} \\
& +\lambda_{2} \sum_{t=1}^{N}\left(\sum_{j=1}^{N_{c}} H_{j, t}^{\mathrm{CHP}}+\sum_{k=1}^{N_{h}} H_{k, t}^{H}-H_{D, t}\right)^{2}
\end{aligned}
$$

where $\lambda_{1}$ and $\lambda_{2}$ are penalty values. Then the objective is to find $f_{\text {min }}$, the minimum evaluation value of all the individuals in all iterations. The penalty term reflects the violation of the equality constraints. Once the minimum of $f$ is reached, the equality constraints are satisfied.

\section{Sequential Quadratic Programming Method}

SQP method can be considered as one of the best nonlinear programming method for constrained optimization problems [28]. It outperforms every other nonlinear programming method in terms of efficiency, accuracy, and percentage of successful solutions over a large number of test problems. The method closely resembles Newton's method for constrained optimization, just as is done for unconstrained optimization. At each iteration, an approximation is made of the Hessian of the Lagrangian function using BroydenFletcher-Goldfarb-Shanno (BFGS) quasi-Newton updating method. The result of the approximation is then used to generate a Quadratic Programming (QP) subproblem whose 
TABLE 3: Hourly heat and power schedule obtained from CHPDED using DE-SQP for eleven-unit system.

\begin{tabular}{|c|c|c|c|c|c|c|c|c|c|c|c|c|c|c|}
\hline & $P_{1}^{\mathrm{TU}}$ & $P_{2}^{\mathrm{TU}}$ & $P_{3}^{\mathrm{TU}}$ & $P_{4}^{1 \mathrm{U}}$ & $P_{5}$ & $P_{6}$ & $P_{7}$ & $P_{8}$ & $P_{1}$ & & oss & $\Pi_{1}$ & $H_{2}$ & $N_{1}$ \\
\hline & 50.000 & & 5372 & & & & & & & & & & 4 & \\
\hline & & & & & & & & & & & & & & \\
\hline & & & & & & & & & & & & & & \\
\hline & & & & & & & & & & & & & & \\
\hline & 00 & & & & & & & & & & & & & \\
\hline & & & & & & & & & & & & & & \\
\hline & 150 & & & & & & & & & & & & & \\
\hline & & & & & & & & & & & & & & \\
\hline & & & & & & & & & & & & & & \\
\hline & 303. & 52 & & & 00 & & & & & & & & & \\
\hline & 17 & & & & & & & & & & & & & \\
\hline & & & & & & & & & & & & & & \\
\hline & 71 & 34 & & & & & & & & & & & & \\
\hline & 71 & 4 & & & & & & & & & & & & \\
\hline & & & & & & & & & & & & & & \\
\hline & 00 & & & & & & & & & & & & & \\
\hline & 00 & & & & & & & & & & & & & \\
\hline & $0^{2}+2$ & & & & & & & & & & & & & \\
\hline & 41 & 231.0 & & & & & & & & & & & & \\
\hline & & & & & & & & & & & & & & \\
\hline & 77 & 300. & & & & & & & & & & & & \\
\hline & & & & & & & & & & & & & & \\
\hline & 00 & & & & & & & & & & & & 94 & 026 \\
\hline & 000 & 作 & 00.6669 & 177.0362 & 123.2649 & 00 & 72.0310 & 0.0000 & 2 & 107.0024 & 27.1007 & 69.4190 & 135.0J15 & 100.0251 \\
\hline
\end{tabular}

Cost $(\$)=2.5257 \times 10^{6} ;$ total loss $(\mathrm{MW})=1.3443 \times 10^{3}$.

solution is used to form a search direction for a line search procedure. Since the objective function of the CHPDED problem is nonconvex and nonsmooth, SQP ensures a local minimum for an initial solution. In this paper, DE is used as a global search and finally the best solution obtained from DE is given as initial condition for SQP method as a local search to fine-tune the solution. SQP simulations can be computed by the fmincon code of the MATLAB Optimization Toolbox.

\section{Simulation Results}

In this section, we present an eleven-unit test system. The hybrid DE-SQP method is applied to the CHPDED problem, where three types of generating units, conventional thermal units, CHP units, and heat-only units, are considered. In DESQP method, the control parameters are chosen as $N P=$ 80, $\mathscr{F}=0.423$, and $C R=0.885$. The maximum number of iterations is selected as 20,000 . The results represent the average of 30 runs of the proposed method. All computations are carried out by MATLAB program.

Eleven-Unit System. This system consists of eight conventional thermal units, two CHP units, and one heat-only unit. The CHPDED problem is solved by hybrid DE-SQP method. The technical data of conventional thermal units, the matrix $B$, and the power demand are taken from the ten-unit system presented in [27]. The 5th and 8th conventional units in [27] were replaced by two CHP units. The technical data of the two

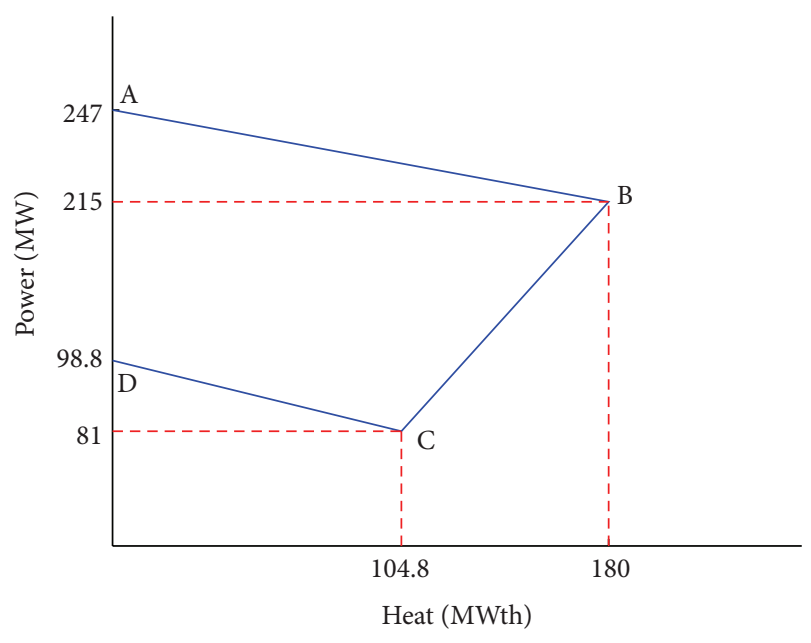

FIGURE 1: Heat-power feasible operating region for CHP unit 1 of the eleven-unit system.

CHP units and the heat-only unit are taken from [19] and are given in Table 1. The heat demand for 24 hours is given in Table 2. The feasible operating regions of the two CHP units are taken from [3] and are given in Figures 1 and 2.

The best solution of the CHPDED problem obtained by DE-SQP algorithm is given in Table 3. The best cost and transmission line losses are also given in Table 3. 


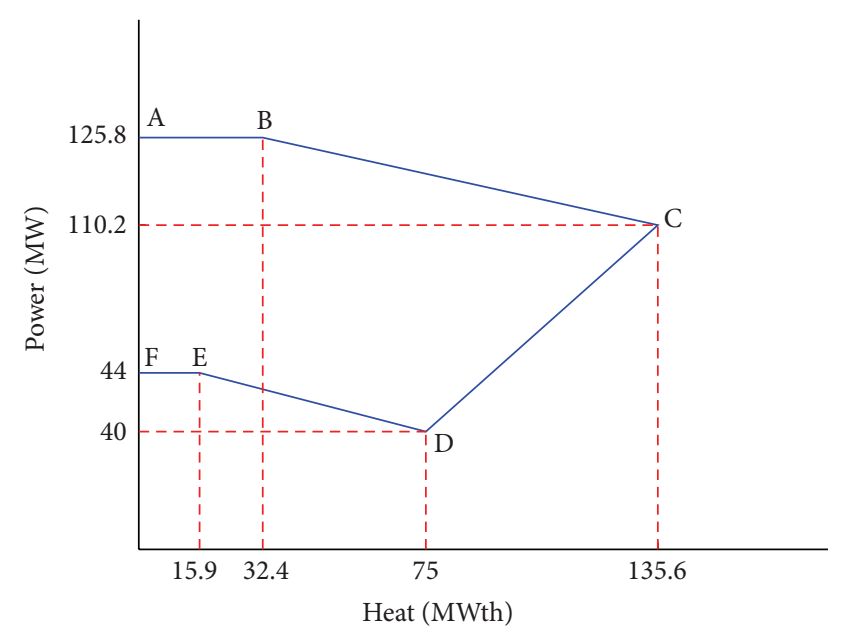

FIGURE 2: Heat-power feasible operating region for CHP unit 2 of the eleven-unit system.

\section{Conclusion}

This paper presents a hybrid method combining DE and SQP for solving the CHPDED problem with valve-point effects. In this paper, $\mathrm{DE}$ is first applied to find the best solution. This best solution is given to SQP as an initial condition to fine-tune the optimal solution at the final. The feasibility and efficiency of the DE-SQP were illustrated by conducting case study with eleven-unit test system.

\section{Acknowledgments}

This paper was funded by the Deanship of Scientific Research (DSR), King Abdulaziz University, Jeddah, Saudi Arabia. The authors, therefore, acknowledge the DSR technical and financial support. The authors are grateful to the anonymous reviewers for constructive suggestions and valuable comments, which improved the quality of the paper.

\section{References}

[1] A. Vasebi, M. Fesanghary, and S. M. T. Bathaee, "Combined heat and power economic dispatch by harmony search algorithm," International Journal of Electrical Power and Energy Systems, vol. 29, no. 10, pp. 713-719, 2007.

[2] P. Subbaraj, R. Rengaraj, and S. Salivahanan, "Enhancement of combined heat and power economic dispatch using self adaptive real-coded genetic algorithm," Applied Energy, vol. 86, no. 6, pp. 915-921, 2009.

[3] T. Guo, M. I. Henwood, and M. van Ooijen, "An algorithm for combined heat and power economic dispatch," IEEE Transactions on Power Systems, vol. 11, no. 4, pp. 1778-1784, 1996.

[4] A. Sashirekha, J. Pasupuleti, N. H. Moin, and C. S. Tan, "Combined heat and power (CHP) economic dispatch solved using Lagrangian relaxation with surrogate subgradient multiplier updates," International Journal of Electrical Power \& Energy Systems, vol. 44, pp. 421-430, 2013.

[5] A. M. Jubril, A. O. Adediji, and O. A. Olaniyan, "Solving the combined heat and power dispatchproblem: a semi-definite programming approach," Power Component Systems, vol. 40, pp. 1362-1376, 2012.

[6] V. N. Dieu and W. Ongsakul, "Augmented lagrangehopfield network for economic load dispatch with combined heat and power," Electric Power Components and Systems, vol. 37, no. 12, pp. 1289-1304, 2009.

[7] E. Khorram and M. Jaberipour, "Harmony search algorithm for solving combined heat and power economic dispatch problems," Energy Conversion and Management, vol. 52, no. 2, pp. 1550-1554, 2011.

[8] C.-T. Su and C.-L. Chiang, "An incorporated algorithm for combined heat and power economic dispatch," Electric Power Systems Research, vol. 69, no. 2-3, pp. 187-195, 2004.

[9] Y. H. Song, C. S. Chou, and T. J. Stonham, "Combined heat and power economic dispatch by improved ant colony search algorithm," Electric Power Systems Research, vol. 52, no. 2, pp. 115-121, 1999.

[10] S. S. Sadat Hosseini, A. Jafarnejad, A. H. Behrooz, and A. H. Gandomi, "Combined heat and power economic dispatch by mesh adaptive direct search algorithm," Expert Systems with Applications, vol. 38, no. 6, pp. 6556-6564, 2011.

[11] M. Behnam, M. Mohammad, and R. Abbas, "Combined heat and power economic dispatch problem solution using particle swarm optimization with time varying acceleration coefficients," Electric Power Systems Research, vol. 95, pp. 9-18, 2013.

[12] V. Ramesh, T. Jayabarathi, N. Shrivastava, and A. Baska, "A novel selective particle swarm optimization approach for combined heat and power economic dispatch," Electric Power Components and Systems, vol. 37, no. 11, pp. 1231-1240, 2009.

[13] M. Basu, "Artificial immune system for combined heat and power economic dispatch," International Journal of Electrical Power \& Energy Systems, vol. 43, pp. 1-5, 2012.

[14] K. P. Wong and C. Algie, "Evolutionary programming approach for combined heat and power dispatch," Electric Power Systems Research, vol. 61, no. 3, pp. 227-232, 2002.

[15] B. Bahmani-Firouzi, E. Farjah, and A. Seifi, "A new algorithm for combined heat and power dynamic economic dispatch considering valve-point effects," Energy, vol. 52, pp. 320-332, 2013.

[16] X. Xia and A. M. Elaiw, "Optimal dynamic economic dispatch of generation: a review," Electric Power Systems Research, vol. 80, no. 8, pp. 975-986, 2010.

[17] P. Attaviriyanupap, H. Kita, E. Tanaka, and J. Hasegawa, "A hybrid EP and SQP for dynamic economic dispatch with nonsmooth fuel cost function," IEEE Transactions on Power Systems, vol. 17, no. 2, pp. 411-416, 2002.

[18] A. M. Elaiw, X. Xia, and A. M. Shehata, "Application of model predictive control to optimal dynamic dispatch of generation with emission limitations," Electric Power Systems Research, vol. 84, no. 1, pp. 31-44, 2012.

[19] T. Niknam, R. Azizipanah-Abarghooee, A. Roosta, and B. Amiri, "A new multi-objective reserve constrained combined heat and power dynamic economic emission dispatch," Energy, vol. 42, no. 1, pp. 530-545, 2012.

[20] R. Storn and K. Price, "Differential evolution-a simple and efficient heuristic for global optimization over continuous spaces," Journal of Global Optimization, vol. 11, no. 4, pp. 341359, 1997.

[21] M. Basu, "Combined heat and power economic dispatch by using differential evolution," Electric Power Components and Systems, vol. 38, no. 8, pp. 996-1004, 2010. 
[22] A. M. Elaiw, X. Xia, and A. M. Shehata, "Dynamic economic dispatch using hybrid DE-SQP for generating units with valvepoint effects," Mathematical Problems in Engineering, vol. 2012, Article ID 184986, 10 pages, 2012.

[23] A. M. Elaiw, X. Xia, and A. M. Shehata, "Hybrid DE-SQP and hybrid PSO-SQP methods for solvin dynamic economic emission dispatch problem with valve-point effects," Electric Power Systems Research, vol. 84, pp. 192-200, 2013.

[24] X. Xia, J. Zhang, and A. Elaiw, "An application of model predictive control to the dynamic economic dispatch of power generation," Control Engineering Practice, vol. 19, no. 6, pp. 638648, 2011.

[25] A. M. Elaiw, X. Xia, and A. M. Shehata, "Minimization of fuel costs and gaseous emissions of electric power generation by model predictive control," Mathematical Problems in Engineering, vol. 2013, Article ID 906958, 15 pages, 2013.

[26] C. K. Panigrahi, P. K. Chattopadhyay, R. N. Chakrabarti, and M. Basu, "Simulated annealing technique for dynamic economic dispatch," Electric Power Components and Systems, vol. 34, no. 5, pp. 577-586, 2006.

[27] M. Basu, "Dynamic economic emission dispatch using nondominted sorting genetic algorthim-II," International Journal of Electrical Power \& Energy Systems, vol. 30, no. 2, pp. 140-149, 2008.

[28] P. T. Boggs and J. W. Tolle, "Sequential quadratic programming," Acta Numerica, vol. 3, no. 4, pp. 1-52, 1995. 


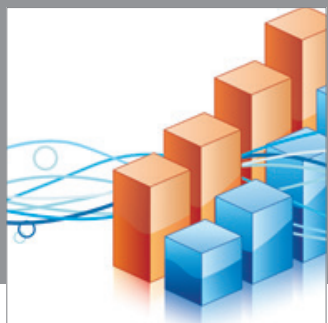

Advances in

Operations Research

mansans

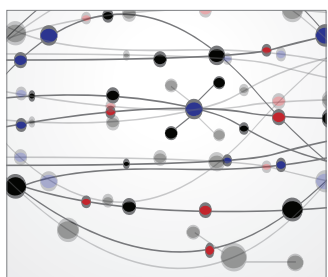

The Scientific World Journal
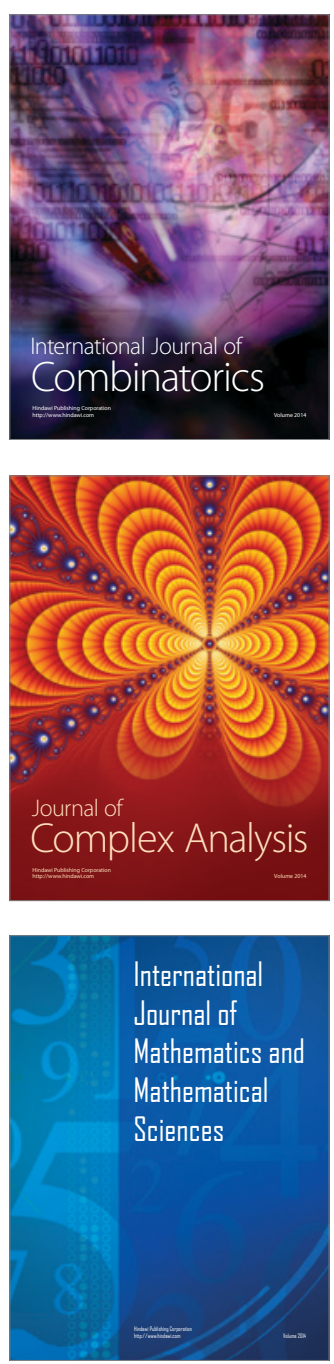
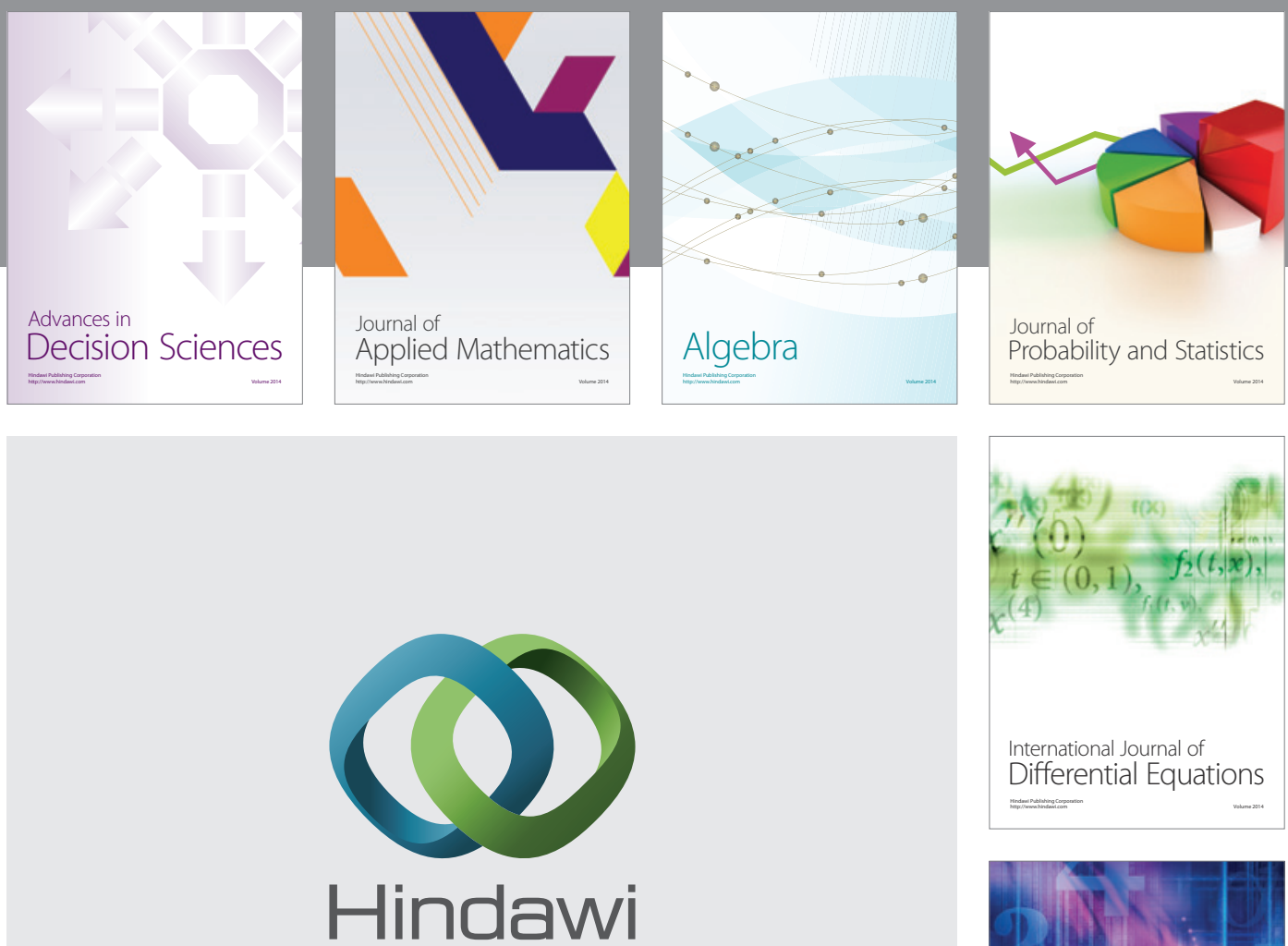

Submit your manuscripts at http://www.hindawi.com
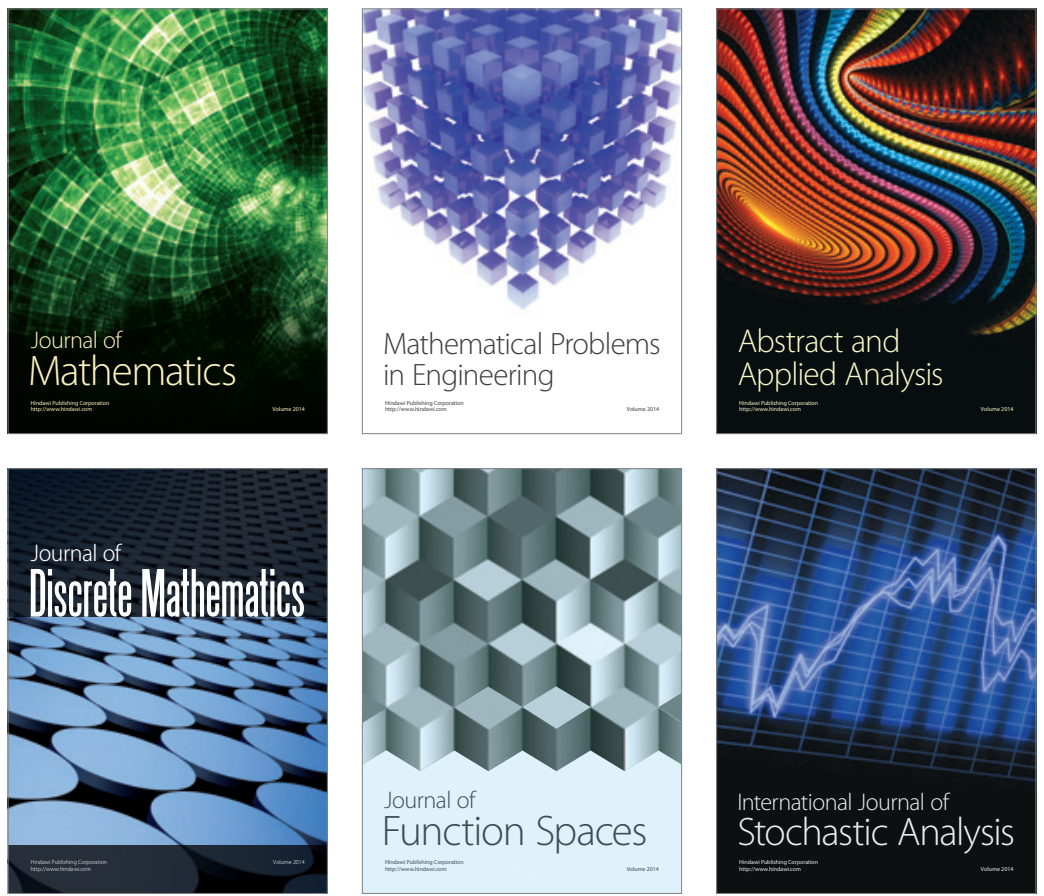

Journal of

Function Spaces

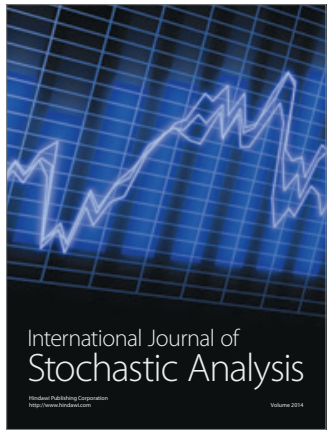

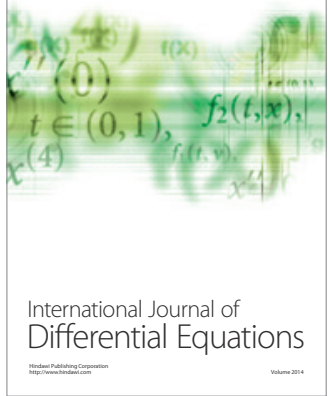
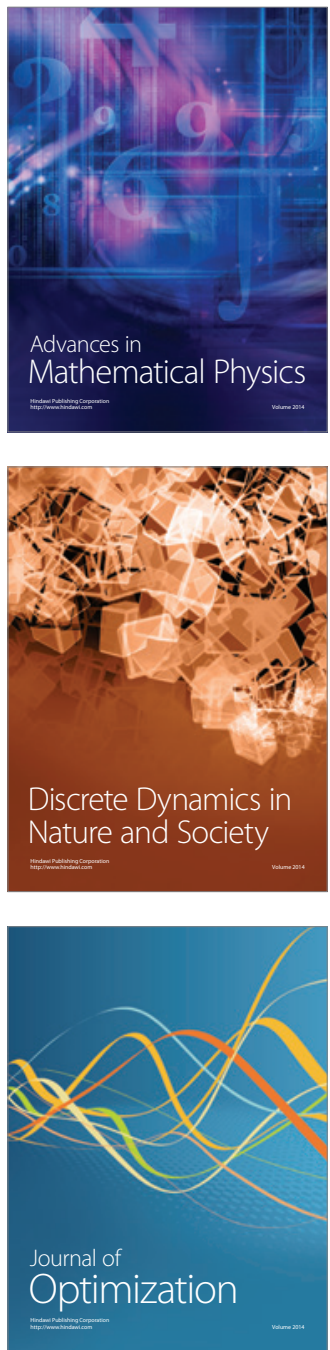